\title{
Persulfate Oxidation for the Remediation of Petroleum Hydrocarbon-Contaminated Soils
}

\author{
Hao Wu, Lina Sun*, Hui Wang, Xiaoxu Wang \\ Key Laboratory of Regional Environment and Eco-Remediation, Ministry of Education, Shenyang University, \\ Shenyang, Liaoning 110044, China
}

Received: 14 July 2015

Accepted: 1 December 2015

\begin{abstract}
The feasibility of total petroleum hydrocarbon-contaminated (TPH) soil remediation was studied using persulfate oxidation. Factors tested included type of activator, persulfate concentration, number of persulfate applications, and reaction time. Probe chemicals were used to study efficiency of the persulfate oxidation mechanism. The best activation method used $\mathrm{Fe}^{2+}$, which achieved $40.8 \% \mathrm{TPH}$ degradation at $24 \mathrm{~h}$ with an initial TPH concentration of $14,432.5 \mathrm{mg} / \mathrm{kg}$. For alkaline (high $\mathrm{pH}$ ) and hydrogen peroxide activation treatments, TPH degradation efficiencies were $35.2 \%$ and $21 \%$, respectively. Thermal activation efficiency was relatively low (15.6\%). Kinetic experiments demonstrated that the oxidation reaction was substantially completed within $60 \mathrm{~min}$. A one-time addition of persulfate was superior to multiple applications. The addition of probe compounds produced sulfate radicals, hydroxyl radicals, and reductants. The results indicate that activated persulfate is reasonably effective for remediation of TPH-contaminated soils.
\end{abstract}

Keywords: chemical oxidation, total petroleum hydrocarbon (TPH), sodium persulfate

\section{Introduction}

Soil contamination by petroleum hydrocarbons is a serious and widespread problem. Petroleum oil is a class of organic molecules extracted by carbon tetrachloride without adsorption of magnesium silicate under specified conditions, and has all or part of the characteristic absorption in $2930 \mathrm{~cm}^{-1}, 2960 \mathrm{~cm}^{-1}$, and $3030 \mathrm{~cm}^{-1}$ wave bands [1]. The total petroleum hydrocarbons (TPH) of urban industrial-contaminated sites includes mainly alkane, aromatic hydrocarbon, and non-hydrocarbon substances (pyridine, organic acids, phenol, ketone, etc.). Petroleum oil exists widely in the soil, which could damage the ecological environmental system and also human

*e-mail: zhu13mao@163.com health. Therefore, remediation for TPH-contaminated soils is required. However, remediation for the long-term TPH-contaminated soils is much more difficult due to the high hydrophobicity, low volatility, and solubility of TPH.

A survey of 34 in-situ chemical oxidation (ISCO) remediation projects showed that TPH was found in more than $60 \%$ of the sites in the US between 2011 and 2013 [2]. Various technologies such as excavation followed by landfilling or incineration, bioremediation [3], surfactant ousting [4], soil vapor extraction, and chemical oxidation [5] have been applied. In consideration of cost effectiveness and time constraints, we decided to apply chemical oxidation for soil remediation. In-situ chemical oxidation (ISCO) is an effective soil remediation technology, and has been applied to many organic-contaminated sites [6].

Sodium persulfate $\left(\mathrm{Na}_{2} \mathrm{~S}_{2} \mathrm{O}_{8}\right)$ is a strong $\left(\mathrm{E}_{0}=2.01 \mathrm{~V}\right)$ water-soluble $\left(560 \mathrm{~g} \cdot \mathrm{L}^{-1}\right)$ oxidant. After activation (i.e., 
thermal, UV light, transition metals, base, $\mathrm{H}_{2} \mathrm{O}_{2}$ ), the more powerful oxidants $\mathrm{SO}_{4} \cdot{ }^{-}\left(\mathrm{E}_{0}=2.4 \mathrm{~V}\right)$ and $\cdot \mathrm{OH}\left(\mathrm{E}_{0}=2.8 \mathrm{~V}\right)$ can be generated. It can destroy organic contaminates with wide range [7]. But there are few studies on the treatment of long-term TPH-contaminated soil with more complex composition, using in-situ persulfate oxidation.

Batch experiments were conducted under laboratory conditions to evaluate the feasibility of remediating longterm TPH-contaminated soil using persulfate oxidation. The objectives were to:

1) compare the efficiencies of $\mathrm{TPH}$ removal using different activation methods,

2) evaluate different persulfate concentrations on TPH removal,

3) evaluate the effects of soil $\mathrm{pH}$ and persulfate addition methods on TPH removal.

\section{Materials and Methods}

\section{Materials}

TPH-contaminated soil was collected from a former fuel storage warehouse in Dalian, China. The warehouse had been used for fuel storage for $\sim 20$ years. TPH concentrations ranged from 220 to $18,500 \mathrm{mg} / \mathrm{kg}$ in soil samples from the warehouse. According to Chinese Environmental Quality Standards of Soils (GB 15618-2008), this TPHcontaminated site requires remediation. A large pit was excavated on the central portion of the site and soil samples $(0 \sim 30 \mathrm{~cm})$ were collected from inside the pit.

The soil samples were air dried, ground, homogenized, and sieved (2-mm sieve) to assure uniformity. Subsamples were sealed and stored at $-4^{\circ} \mathrm{C}$ until used. Soil properties are listed in Table 1. The mean TPH concentration in the soil samples was $14,432.5 \mathrm{mg} / \mathrm{kg}$. This value was used as the initial TPH concentration in the laboratory studies.

TPH standard sample $\left(1 \mathrm{mg} \cdot \mathrm{L}^{-1}\right)$ was obtained from the China Institute of Metrology. Carbon tetrachloride

Table 1. Properties of test soil from the contaminated site.

\begin{tabular}{|c|c|c|}
\hline Properties & Values & Method \\
\hline $\mathrm{TPH}(\mathrm{mg} / \mathrm{kg})$ & 14432.5 & Infrared spectrophotometric \\
\hline $\mathrm{pH}$ & 7.1 & ph meter \\
\hline $\begin{array}{c}\text { Total Organic } \\
\text { carbon }(\%)\end{array}$ & 1.8 & $\begin{array}{c}\text { High temperature oxidation } \\
\text { of potassium dichromate } \\
\text { volumetric method }\end{array}$ \\
\hline $\mathrm{Fe}^{2+}(\mathrm{mg} / \mathrm{kg})$ & 154 & Phenanthroline colorimetry \\
\hline $\mathrm{Mn}^{2+}(\mathrm{mg} / \mathrm{kg})$ & 20.4 & $\begin{array}{c}\text { Potassium periodate } \\
\text { colorimetry }\end{array}$ \\
\hline Partial size $^{2}$ & Silty sand & Laser particle analyzer \\
\hline Sand $(\%)$ & 60.54 & \\
\hline Clay $(\%)$ & 37.01 & \\
\hline Silt $(\%)$ & 2.46 & \\
\hline
\end{tabular}

$\left(\mathrm{CCl}_{4}\right.$, for IR) was purchased from China Tianjin Bodi Chemicals. Sodium persulfate $\left(\mathrm{Na}_{2} \mathrm{~S}_{2} \mathrm{O}_{8},>99 \%\right.$; China Pharmaceutical Group) was used as the oxidant. Ferrous sulfate $\left(\mathrm{FeSO}_{4} \cdot 7 \mathrm{H}_{2} \mathrm{O}, 99 \%\right.$, China Pharmaceutical Group) was used to activate the persulfate.

\section{Experimental Design \\ Persulfate Oxidation Parameter Screening Experiments}

Four groups of experiments were performed to evaluate the effectiveness of different treatments for TPH remediation (Table 2). The ranges of temperature, moles activator/moles persulfate, and $\mathrm{pH}$ were determined as described previously [8]. The thermal activation experiments were performed at room temperature $\left(\sim 25^{\circ} \mathrm{C}\right)$. The concentrations of $\mathrm{Na}_{2} \mathrm{~S}_{2} \mathrm{O}_{8}, \mathrm{FeSO}_{4}$, and citric acid (CA) were $1,0.5$, and $0.5 \mathrm{~mol} / \mathrm{L}$, respectively. All experiments were performed in triplicate. The data presented in text and figures are the mean values of the results.

Contaminated soil $(10 \mathrm{~g})$ was placed into a $150-\mathrm{mL}$ conical flask and persulfate, activator, and deionized (DI) water were sequentially added. In the bench experiments the soil:liquid ratio was 1:5. After the addition of each solution, the test reactors were spun in the vortex oscillator for $4 \mathrm{~h}$ to assure complete mixing, then removed to allow completion of the reaction. Then the mixtures were separated by centrifuge. Supernatant samples were analyzed for persulfate and TPH concentrations, temperature, and $\mathrm{pH}$. Soil samples were analyzed for TPH concentration.

\section{Parameter Optimization and Dominant Radical Oxidant Detection Experiments}

Three parameters, including amount and timing of sodium persulfate addition and soil $\mathrm{pH}$, were evaluated (Table 3). The experimental methods were similar to persulfate oxidation parameter screening experiments,

Based on results of the persulfate oxidation parameter screening experiments [9], the optimal activation conditions for TPH oxidation were used for advanced studies. Probe compounds were used to identify the type of radicals. Ethanol (EtOH) was used to detect both hydroxyl radicals and sulfate radicals $\left(\mathrm{k}_{\mathrm{OH}}=1.2 \sim 2.8 \times 10^{9}\right.$ $\mathrm{M}^{-1} \mathrm{~s}^{-1} ; \mathrm{k}_{\mathrm{SO} 4 \cdot-}=1.6 \sim 7.7 \times 10^{7} \mathrm{M}^{-1} \mathrm{~s}^{-1}$ ) [10]. Nitrobenzene (NB) was used because it is highly reactive with hydroxyl radicals but unreactive with sulfate radicals $\left(\mathrm{k}_{\mathrm{OH}} \cdot=3.9\right.$ $\left.\times 10^{9} \mathrm{M}^{-1} \mathrm{~s}^{-1} ; \mathrm{k}_{\mathrm{SO} 4}{ }^{-}<10^{6} \mathrm{M}^{-1} \mathrm{~s}^{-1}\right)$ [11]. Hexachloroethane (HCA) was used as a reductant probe because it is readily degraded by the reductant superoxide in the presence of cosolvents [12]. HCA is reduced by alkyl radicals but it is not oxidized by the hydroxyl radical $\left(\mathrm{k}_{\mathrm{OH}} \leq 10^{6} \mathrm{M}^{-1} \mathrm{~s}^{-1}\right)$.

Reactions consisted of a $50 \mathrm{~mL}$ solution of $1 \mathrm{M}$ sodium persulfate, $0.5 \mathrm{M}$ ferrous iron, $0.5 \mathrm{M}$ citric acid, and $1 \mathrm{mM}$ of the probe compounds. Control reactions were conducted using deionized water. All reactions were replicated three times and the data were reported as the mean of the three replicates. 
Table 2. Parameters, conditions, and approaches used in persulfate oxidation parameter screening experiments.

\begin{tabular}{|c|c|c|c|c|c|}
\hline & Activator & persulfate/ activator ratios & $\mathrm{pH}$ & Temperature & Remarks \\
\hline 1 & \multirow{2}{*}{ No activator } & & & \multirow{2}{*}{$\begin{array}{l}\text { Ambient } \\
\text { Ambient }\end{array}$} & Persulfate free \\
\hline 2 & & & & & Un-activated persulfate \\
\hline 3 & \multirow{3}{*}{ Temperature } & & & $40^{\circ} \mathrm{C}$ & \multirow{3}{*}{ Water bath } \\
\hline 4 & & & & $70^{\circ} \mathrm{C}$ & \\
\hline 5 & & & & $100^{\circ} \mathrm{C}$ & \\
\hline 6 & \multirow{3}{*}{$\mathrm{CA} / \mathrm{Fe}^{2+}(0.5 \mathrm{M})$} & 10 & & \multirow{3}{*}{ Ambient } & \multirow{3}{*}{ Mixed } \\
\hline 7 & & 4 & & & \\
\hline 8 & & 1 & & & \\
\hline 9 & \multirow{3}{*}{$\mathrm{H}_{2} \mathrm{O}_{2}(30 \%)$} & 100 & & \multirow{3}{*}{ Ambient } & \multirow{3}{*}{ Mixed } \\
\hline 10 & & 10 & & & \\
\hline 11 & & 1 & & & \\
\hline 12 & \multirow{3}{*}{$\mathrm{pH}$} & & 9 & \multirow{3}{*}{ Ambient } & \multirow{3}{*}{ Adjusted $\mathrm{pH}$ using $\mathrm{NaOH}(3 \mathrm{M})$} \\
\hline 13 & & & 11 & & \\
\hline 14 & & & 12 & & \\
\hline
\end{tabular}

\section{Sample Analysis}

Soil samples from each test reaction were freeze-dried, combined with anhydrous sodium sulfate $(10 \mathrm{~g})$, and mixed with tetrachloromethane $(20 \mathrm{~mL})$. The mixture was ultrasonically extracted (30 min). Subsequently, magnesium silicate was put into the reactors and vibrated $(60 \mathrm{~min})$. The resulting mixture was collected in a $50-\mathrm{mL}$ glass tube after

Table 3. TPH degradation in treatments and in radical detection experiments.

\begin{tabular}{|c|c|c|c|}
\hline Experiments & Setting & $\mathrm{pH}$ & Remarks \\
\hline \multirow{6}{*}{$\begin{array}{l}\text { The amount } \\
\text { of sodium } \\
\text { persulfate }\end{array}$} & $0.5 \mathrm{mmol} / \mathrm{g}$ soil & \multirow{6}{*}{7.1} & \\
\hline & $1 \mathrm{mmol} / \mathrm{g}$ soil & & \\
\hline & $1.5 \mathrm{mmol} / \mathrm{g}$ soil & & \\
\hline & $2 \mathrm{mmol} / \mathrm{g}$ soil & & \\
\hline & $2.5 \mathrm{mmol} / \mathrm{g}$ soil & & \\
\hline & $3 \mathrm{mmol} / \mathrm{g}$ soil & & \\
\hline \multirow{3}{*}{$\begin{array}{l}\text { Adding } \\
\text { methods }\end{array}$} & 1 time & \multirow{3}{*}{7.1} & \multirow{3}{*}{$\begin{array}{l}\text { The same amount } \\
\text { of oxidant, the } \\
\text { time interval was } \\
60 \text { min. }\end{array}$} \\
\hline & 2 times & & \\
\hline & 3 times & & \\
\hline \multirow{3}{*}{$\begin{array}{l}\text { Probe } \\
\text { chemicals }\end{array}$} & $\begin{array}{l}\text { Nitrobenzene } \\
\text { (NB) }\end{array}$ & \multirow{3}{*}{7.1} & \\
\hline & $\begin{array}{l}\text { Ethanol } \\
(\text { EtOH })\end{array}$ & & \\
\hline & $\begin{array}{c}\text { Hexachloroethane } \\
\text { (HCA) }\end{array}$ & & \\
\hline
\end{tabular}

passing through a glass fiber filter. TPH concentrations were analyzed by infrared spectrophotometry [13].

The concentration of TPH in the supernatant was measured by liquid-liquid extraction. The supernatant was transferred to a $250 \mathrm{~mL}$ whole separating funnel with a Teflon valve, $20 \mathrm{~mL}$ carbon tetrachloride was added, and the extract was filtered through a glass fiber filter volume to $50 \mathrm{~mL}$ [1].

Infrared was measured using a $40 \mathrm{~mm}$ quartz cuvette with carbon tetrachloride as a reference solution. Absorbance was measured at the wave numbers $3030 \mathrm{~cm}^{-1}, 2960 \mathrm{~cm}^{-1}$, and $2930 \mathrm{~cm}^{-1}$.

Persulfate concentrations in aqueous samples were measured by placing a $0.1 \mathrm{~mL}$ sample into a $20 \mathrm{~mL}$ test tube. Then, $0.9 \mathrm{~mL}$ DI water, $10 \mathrm{~mL} 1.25 \mathrm{M} \mathrm{H}_{2} \mathrm{SO}_{4}$, and $0.1 \mathrm{~mL} 0.4 \mathrm{M}$ ferrous ammonium sulfate (FAS) were added. The contents were mixed and allowed to react for $40 \mathrm{~min}$. Then, $0.2 \mathrm{~mL} 0.6 \mathrm{M}$ ammonium thiocyanate $\left(\mathrm{NH}_{4} \mathrm{SCN}\right)$ was added, and the absorbance was measured with a spectrophotometer (Varian Cary 40, USA) at a wavelength of $450 \mathrm{~nm}$. A calibration curve established by these procedures ranged from 5 to $100 \mathrm{mg} / \mathrm{L}$ with a linear correlation coefficient $\left(\mathrm{R}^{2}>0.99\right)[14]$.

\section{Results and Discussion}

\section{TPH Degradation Efficiency of Different Activation Methods}

In the control treatment (no oxidant addition), TPH removal was not observed (Fig. 1). This indicated that water alone was ineffective for remediation of the contaminated soil. Because the soils contained mainly 
sandy silt and silty loam, contaminants were strongly sorbed onto soil particles and may not have been dislodged by water washing.

Removal of TPH from soil using sodium persulfate activated by $\mathrm{Fe}^{2+}$ or alkaline conditions produced removal rates of $40.8 \%$ and $35.2 \%$, respectively. Hydrogen peroxide activation produced a maximum removal rate of $25.6 \%$. Heat activation produced a removal rate of $15.6 \%$. The test soil had been contaminated for $>20$ years and the level of contaminant binding was assumed to be strong. Previous studies demonstrated that sodium persulfate removed $50 \%$ of artificially added BTEX from soil $[7,8]$. However, removal of BTEX from long-term real contaminated soil was only $13 \%$. This suggests that pollutant adsorption by soil may significantly impact the oxidative degradation of pollutants. Ferrous ion serves as a catalyst and plays an important role in the oxidant reaction. The molar ratios of $\mathrm{S}_{2} \mathrm{O}_{8}{ }^{2-} / \mathrm{Fe}^{2+}$ at $10 / 1,4 / 1$, and $1 / 1$ were applied. Results showed that approximately $40 \%$ of the total TPH removal occurred within $24 \mathrm{~h}$ in all reaction treatments. However, TPH removal was only $3 \%$ in treatments without ferrous ion. This indicates that there were insufficient metal oxides in the soil for the activation of persulfate. TPH removal can be significantly enhanced with an increased concentration of ferrous ions.

Ferrous ion is a scavenger of sulfate free radicals and there was an optimal ratio of $\mathrm{S}_{2} \mathrm{O}_{8}{ }^{2-} / \mathrm{Fe}^{2+}$ in other studies $[15,16]$. In the present study, the $4 / 1$ molar ratio of $\mathrm{S}_{2} \mathrm{O}_{8}{ }^{2-} / \mathrm{Fe}^{2+}$ was optimal.

Alkaline activation methods can produce $\cdot \mathrm{OH}, \mathrm{SO}_{4}{ }^{--}$, and reductant [9]. Previous studies [15, 18] demonstrated that the main active substance is $\mathrm{SO}_{4}{ }^{-}$when $\mathrm{pH}<7$, while the main active substance is $\mathrm{OH}$ when $\mathrm{pH}>12$. The $\cdot \mathrm{OH}$ is a stronger oxidant, which could increase the rate of TPH removal with greater alkalinity. We found that the rate of TPH degradation gradually increased with increased alkalinity. However, this effect was smaller than that of $\mathrm{Fe}^{2+}$ activation. This may be because TPH is locked onto

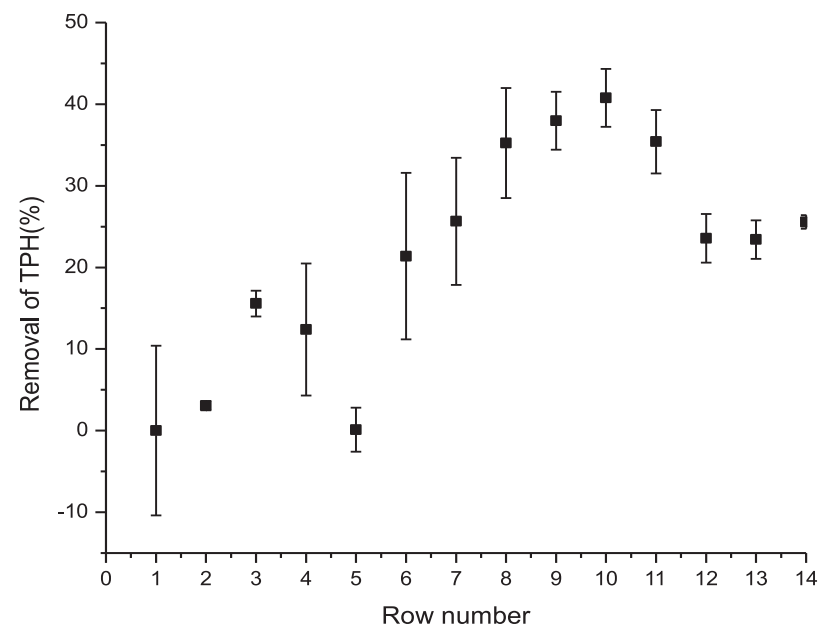

Fig.1. TPH oxidation using different activation methods (initial TPH concentration: $14432.5 \mathrm{mg} / \mathrm{kg}$; persulfate concentration: $2.5 \mathrm{mmol} / \mathrm{g}$ soil). soil particles and $\mathrm{SO}_{4} \cdot{ }^{-}$has longer persistence and provides enhanced contact with contaminants compared to $\cdot \mathrm{OH}$. There may also be some substances in the soil containing nitro $\left(-\mathrm{NO}_{2}\right)$ or carbonyl $(\mathrm{C}=\mathrm{O})$ groups, which could be degraded by $\mathrm{SO}_{4} \cdot{ }^{-}$but do not react with $\cdot \mathrm{OH}[16]$.

As temperature increases, pollutant degradation generally increases [17]. Since sodium persulfate rapidly decomposes at high temperatures to produce $\mathrm{SO}_{4} \cdot{ }^{-}$[18], $\mathrm{SO}_{4}{ }^{-}$can quickly be generated to expedite the conversion of free radicals. Increased temperatures can accelerate reactions. This may help explain the removal rate decrease with increasing temperature. For specific reaction systems, there is an optimal reaction temperature, and higher temperatures are less favorable to the reaction [19]. In this experiment, TPH removal was maximized at $40^{\circ} \mathrm{C}$.

Decomposition of hydrogen peroxide can provide heat for activation of sodium persulfate. The release of $\mathrm{SO}_{4}{ }^{-}$ and $\cdot \mathrm{OH}$ can stimulate hydrogen peroxide-generation of free radicals and the formation of a radical chain reaction of excitation that produces greater oxidizing strength [20, 21]. Hydrogen peroxide activation had a degradation rate of $25.6 \%$, which was significantly less than $\mathrm{Fe}^{2+}$ activation and alkaline activation. The possible reasons for the low efficiency of hydrogen peroxide may be the reduction of free radicals (Eq.1). Sodium persulfate reacts first with hydrogen peroxide, leading to oxidant reduction and a decrease of TPH degradation efficiency (Eq. 2).

$$
\begin{gathered}
2 \mathrm{SO}_{4}^{-\cdot}+2 \mathrm{OH} \cdot \rightarrow 2 \mathrm{SO}_{4}{ }^{2-}+\mathrm{O}_{2} \\
\mathrm{H}_{2} \mathrm{O}_{2}+\mathrm{S}_{2} \mathrm{O}_{8}{ }^{2-}+2 \mathrm{H}^{+} \rightarrow 2 \mathrm{SO}_{4}{ }^{2-}+2 \mathrm{H}_{2} \mathrm{O}
\end{gathered}
$$

\section{TPH Oxidation at Different Persulfate Concentrations}

Sodium persulfate is an important factor in reaction processes and also a major economic factor in an in-situ restoration. TPH removal efficiency from soil at $24 \mathrm{~h}$ significantly increased from $12.8 \%$ to $40.8 \%$, when sodium persulfate addition increased from $0.5 \mathrm{mmol} / \mathrm{g}$ to $2.5 \mathrm{mmol} / \mathrm{g}$ (Fig. 2). TPH removal decreased to $34.78 \%$ when the dosage increased to $3 \mathrm{mmol} / \mathrm{g}$ soil. The increase of TPH removal rate therefore only occurred within a certain concentration range of sodium persulfate. The persulfate concentration may be more rapidly oxidized $\left(\mathrm{Fe}^{2+}\right.$ to $\left.\mathrm{Fe}^{3+}\right)$ when it exceeds optimum levels. This can result in the oxidation reaction, catalyzed by $\mathrm{Fe}^{3+}$, consuming sodium persulfate and also reducing $\mathrm{SO}_{4}{ }^{-}$ generation. High concentrations of sodium persulfate may also lead to increased generation of $\mathrm{SO}_{4}^{-\cdot^{-}}$quenching and affecting TPH removal. The overall results indicated that persulfate oxidation was capable of removing TPH from contaminated soil.

Approximately $60 \%$ of the initial residual TPH remained in the soil following treatment. There was no additional effectiveness gained by using persulfate in amounts greater than $2.5 \mathrm{mmol} / \mathrm{g}$ soil. This might be because: 


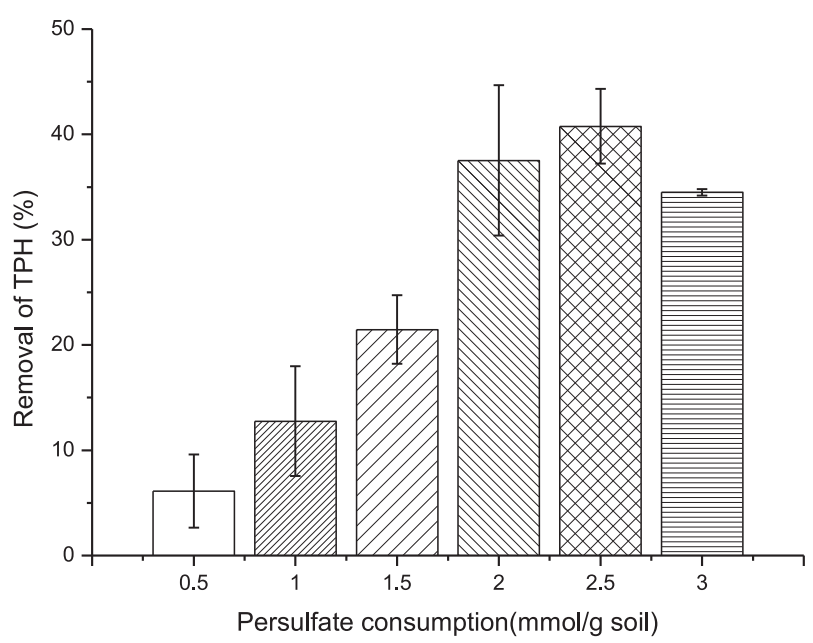

Fig. 2. TPH oxidation at different persulfate concentrations (initial TPH concentrations: $14,432.5 \mathrm{mg} / \mathrm{kg}$; molar ratio of persulfate/ferrous ion: 4/1).

1) the most degradable components of TPH are removed by moderate rates of persulfate while the residual components are more difficult to remove because of their complicated structures [22],

2) adsorption of the TPH onto organic matter and soil micropores make it more difficult to remove [23],

3) $\mathrm{TPH}$ components containing nitro $\left(-\mathrm{NO}_{2}\right)$ or carbonyl $(\mathrm{C}=\mathrm{O})$ would not be susceptible to oxidation by persulfate $\left(\mathrm{SO}_{4} \cdot{ }^{-}\right)$.

Further studies are needed to determine the relevance of these possibilities.

\section{TPH Degradation Related to Frequency of Persulfate Application}

TPH removal was $24.9 \%$ and $0.2 \%$ in the treatments with double and triple applications of sodium persulfate,

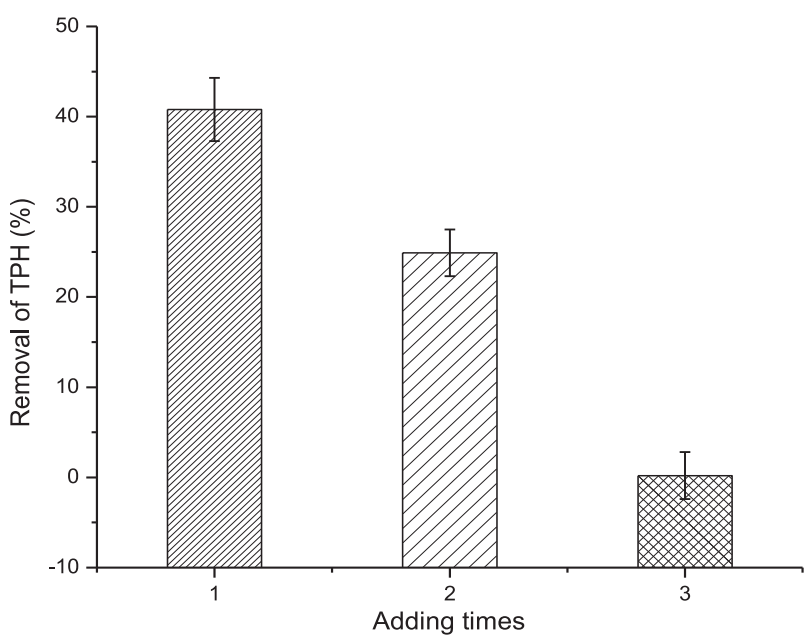

Fig. 3 TPH oxidation achieved by varying frequency of persulfate application (initial TPH concentration: $14,432.5 \mathrm{mg} /$ $\mathrm{kg}$; persulfate concentration: $2.5 \mathrm{mmol} / \mathrm{g}$ soil; molar ratio of persulfate/ferrous ion: 4/1). respectively. These were both significantly less than the $40.8 \%$ achieved in the single application treatment (Fig. 3). This may be due to the insufficient amounts of oxidant, the lack of driving force, and the limitation of $\mathrm{SO}_{4}{ }^{-}$generation. Therefore, in the case of very high concentrations of TPH pollutants, treatment with a relatively high concentration of oxidant may be necessary.

\section{Effects of Persulfate Oxidation for TPH by $\mathrm{Fe}^{2+}$ Activation}

A three-stage TPH oxidation was observed in the tests. Significant degradation occurred in the initial five min during which the TPH removal rate increased rapidly and the sodium persulfate concentration quickly decreased (Fig. 4). At $5 \mathrm{~min}$, the soil TPH concentration decreased from $14,432.3 \mathrm{mg} / \mathrm{kg}$ to $9,903.6 \mathrm{mg} / \mathrm{kg}$, and sodium persulfate decreased from $95.2 \mathrm{~g} / \mathrm{L}$ to $2.5 \mathrm{~g} / \mathrm{L}$. After persulfate addition, $\mathrm{Fe}^{2+}$ catalyzed rapid decomposition of sodium persulfate and produced additional $\mathrm{SO}_{4}^{4^{-}}$, which accelerated TPH degradation. Between five and $60 \mathrm{~min}$, the oxidation rate slowed. From 60 to $480 \mathrm{~min}$, all sodium persulfate was depleted and TPH removal essentially ended with a level of $43.5 \%$. This indicated that the oxidation reaction was substantially completed within the first $60 \mathrm{~min}$. According to the results of a first-order reaction kinetics $\left(\mathrm{C}=\mathrm{C}_{0} \mathrm{e}^{-\mathrm{kt}}\right)$, the rapid reaction rate constant of the sodium persulfate reaction was $0.0753 \mathrm{~min}^{-1}$ and the slow rate constant was 0.0383 $\min ^{-1}$.

\section{Analysis of Free Radicals in} the TPH Removal Reactions

$\mathrm{Fe}^{2+}$-activated persulfate degradation of organic matter is a chain reaction process [24]. We selected three radical probe compounds to evaluate the degradation mechanisms at different time periods and to determine the active process of TPH-oxidized free radicals (Fig. 5).

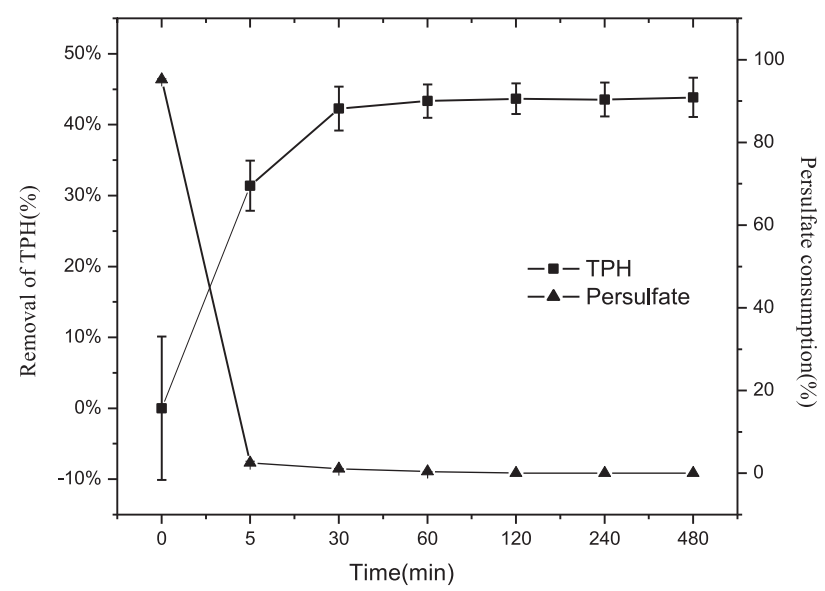

Fig. 4 TPH oxidation in $\mathrm{Na}_{2} \mathrm{~S}_{2} \mathrm{O}_{8} / \mathrm{Fe}^{2+} / \mathrm{CA}$ system (initial TPH concentration: $14432.5 \mathrm{mg} / \mathrm{kg}$; persulfate concentration: $2.5 \mathrm{mmol} / \mathrm{g}$ soil; molar ratio of persulfate/ferrous ion: 4/1). 

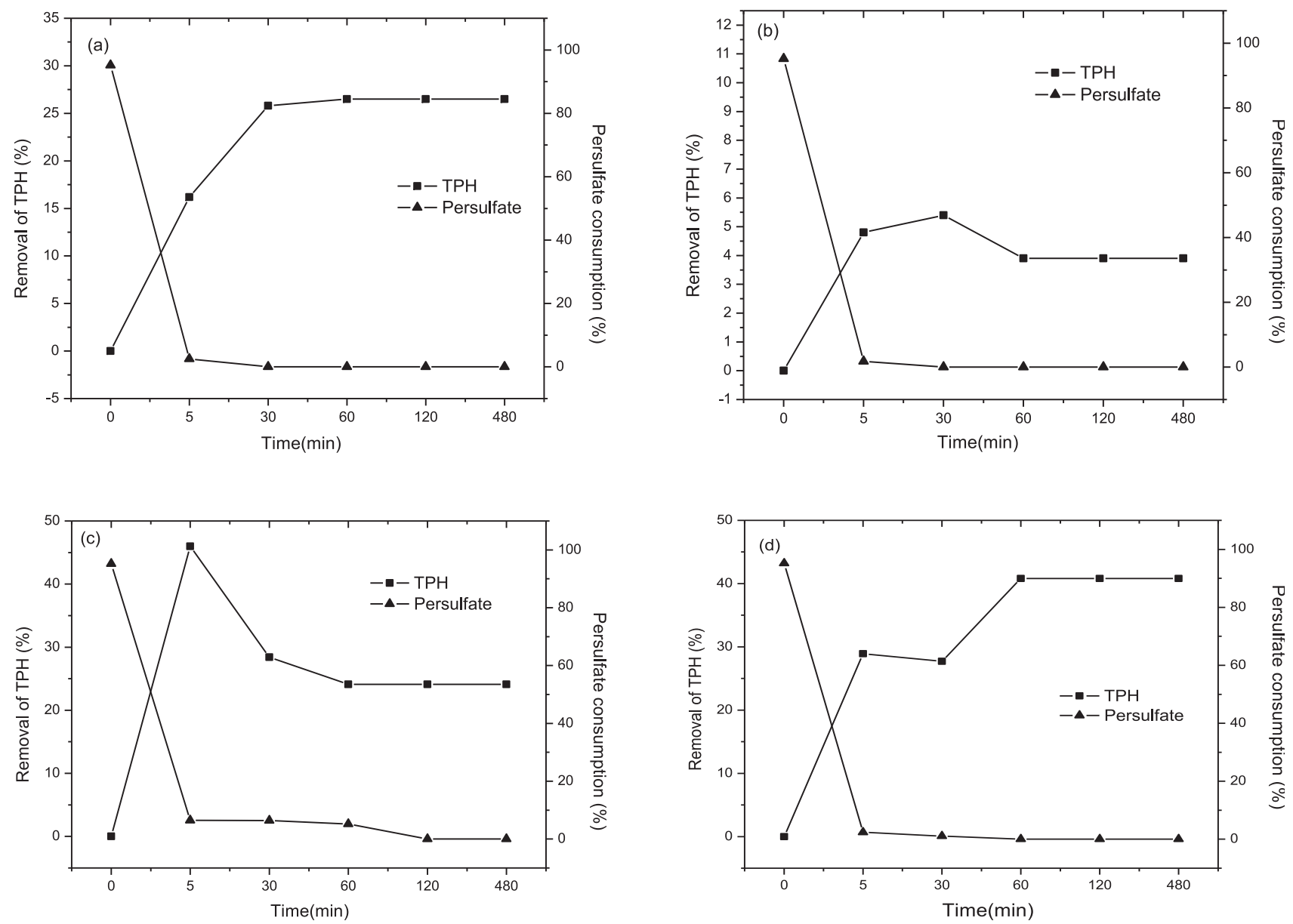

Fig. 5 Radical detection (initial TPH concentration: $14,432.5 \mathrm{mg} / \mathrm{kg}$; persulfate concentration: $2.5 \mathrm{mmol} / \mathrm{g}$ soil; molar ratio of persulfate/ ferrous ion: 4/1). (a) nitrobenzene; (b) ethanol; (c) hexachloroethane; (d) blank.

After addition of the radical inactivating agent ethanol, TPH removal was $8 \%$ at $60 \mathrm{~min}$. This indicated that sodium persulfate itself had some oxidation activity and that contaminants could remove some TPH. After adding the $\cdot \mathrm{OH}$ inactivating agent nitrobenzene, TPH removal was $26.5 \%$ at $60 \mathrm{~min}$. The results were lower than that of $40.8 \%$ without radical scavengers. This indicated the presence of other substances in the $\mathrm{SO}_{4}{ }^{-}$system. After adding HCA, TPH removal was $24.1 \%$ at $60 \mathrm{~min}$, which was lower than the $40.8 \%$ rate for the treatment without radical scavenger removal. This indicated the presence of reducing substances in the system. The addition of reducing substances to the system can therefore contribute to the activation of sodium persulfate degradation.

\section{Conclusions}

Approximately $40 \%$ of soil TPH was removed using a persulfate oxidation process, indicating that chemical oxidation could be applied in-situ to remediate TPHcontaminated soils. Several activation methods were useful, but the addition of $\mathrm{Fe}^{2+}$ was most effective. TPH was not completely removed possibly due to:
1) complicated structures in the residual components of $\mathrm{TPH}$,

2) adsorption of TPH onto organic matter and soil microphones,

3) the existence of TPH components not oxidized by persulfate $\left(\mathrm{SO}_{4}{ }^{-}\right)$.

Repeated applications of persulfate would not be a feasible way to enhance contaminant oxidation. Radical probe experiments demonstrated that the degradation of pollutants in the main TPH material was accomplished by $\mathrm{SO}_{4}{ }^{-}, \cdot \mathrm{OH}$, and certain reducing substances. Adding a reducing substance may contribute to TPH degradation in the reaction system.

\section{Acknowledgements}

This work was financially supported by the National Key Basic Research Program of China (973 Program, No. 2014CB441106), the Shenyang Science and Technology plan project (No. F14-133-9-00), and the Science and Enterprise Competitive Selection Project of Shenyang City (a study on the risk management and remediation technology of urban ecological environments). 


\section{References}

1. People's Republic of China national environmental standards HJ637-2012, water quality oil and animal and vegetable oils by infrared spectrophotometry. Department of Environmental Protection, 2012.

2. EPA. Chemical Oxidation Site Profiles. [EB/OL].http:// www.clu-in.org/products/chemox/search/chem list.cfm. 2015-03-31.

3. LIU P.W.G., WHANG L.M., YANG M.C., CHENG S.S. Biodegradation of diesel-contaminated soil: A soil column study. Journal of the Chinese Institute of Chemical Engineers, 39 (5), 419, 2008.

4. LEE M., KANG H., DO W. Application of nonionic surfactant-enhanced in-situ flushing to a diesel contaminated site. Water research 39 (1), 139, 2005.

5. TSAI T.T., KAO C.M. Treatment of petroleum-hydrocarbon contaminated soils using hydrogen peroxide oxidation catalyzed by waste basic oxygen furnace slag. Journal of hazardous materials, 170 (1), 466, 2009.

6. U.S. Environmental Protection Agency (EPA). Superfund Remedy Report, $14^{\text {th }}$ Edition, 2013.

7. ITRC (Interstate Technology \& Regulatory Council). Technical and Regulatory Guidance for In-situ Chemical Oxidation of Contaminated Soil and Groundwater, $2^{\text {nd }}$ ed. ISCO-2. Washington, D.C.: Interstate Technology \& Regulatory Council, In-situ Chemical Oxidation Team, 2005.

8. ACHUGASIM O., OJINNAKA C., OSUJI L. Assessment of ability of three chemical oxidants to remove hydrocarbons from soils polluted by Bonny Light crude oil. European Chemical Bulletin, 2 (4), 226, 2013.

9. WATTS R.J. Enhanced reactant-contaminant contact through the use of persulfate in-situ chemical oxidation (ISCO), SERDP Project ER-1489 2011.

10. LIANG C., SU H. W. Identification of sulfate and hydroxyl radicals in thermally activated persulfate. Industrial \& Engineering Chemistry Research, 48 (11), 5558, 2009.

11. WALDEMER R.H., TRATNYEK P.G., JOHNSON R.L., NURMI J.T. Oxidation of chlorinated ethenes by heatactivated persulfate: kinetics and products. Environmental Science \& Technology, 41 (3), 1010, 2007.

12. SMITH B., TEEL A.L., WATTS R.J. Identification of the species responsible for the degradation of carbon tetrachloride by modified Fenton's reagent. Environ. Sci. Technol, 38, 5465, 2004.

13. Peoples Republic of China state environmental protection standards.soil petroleum measurement (draft). Department of Environmental Protection, 2012.
14. LIAO X., ZHAO D., YAN X., HULING S.G. Identification of persulfate oxidation products of polycyclic aromatic hydrocarbon during remediation of contaminated soil. Journal of hazardous materials, 276, 26-34, 2014.

15. LIANG C., WANG Z.S., BRUELL C.J. Influence of $\mathrm{pH}$ on persulfate oxidation of TCE at ambient temperatures. Chemosphere, 66 (1), 106, 2007.

16. ZHAO D., LIAO X., YAN X., HULING S.G., CHAI T., TAO $H$. Effect and mechanism of persulfate activated by different methods for PAHs removal in soil. Journal of hazardous materials, 254, 228, 2013.

17. XIE X., ZHANG Y., HUANG W., HUANG S. Degradation kinetics and mechanism of aniline by heat-assisted persulfate oxidation. Journal of Environmental Sciences, 24 (5), 821, 2012.

18. JOHNSON R.L., TRATNYEK P.G., JOHNSON R.O.B. Persulfate persistence under thermal activation conditions. Environmental science \& technology, 42 (24), 9350, 2008.

19. AIKATERINI TSITONAKI. Treatment trains for the remediation of aquifers polluted with MTBE and other xenobiotic compounds. Lyngby: Technical University of Denmark, 2008.

20. CRIMI M.L., TAYLOR J. Experimental evaluation of catalyzed hydrogen peroxide and sodium persulfate for destruction of BTEX contaminants. Soil \& Sediment Contamination, 16 (1), 29, 2007.

21. CRONK G., CARTWRIGHT R. Optimization of a chemical oxidation treatment train process for groundwater remediation. In: Proceedings of the Fifth International Conference on Remediation of Chlorinated and Recalcitrant Compounds,Monterey, CA. Columbus, Ohio: Battelle Press, 2006.

22. GOI A., TRAPIDO M., KULIK N., PALMROTH M.R.T., TUHKANEN T. Ozonation and Fenton treatment for remediation of diesel fuel contaminated soil. Ozone: Science and Engineering, 28 (1), 37, 2006.

23. YEN C.H., CHEN K.F., KAO C.M., LIANG S.H., CHEN T.Y. Application of persulfate to remediate petroleum hydrocarbon-contaminated soil: Feasibility and comparison with common oxidants. Journal of hazardous materials, 186 (2), 2097, 2011.

24. KIM J.K., METCALFE I.S. Investigation of the generation of hydroxyl radicals and their oxidative role in the presence of heterogeneous copper catalysts. Chemosphere, 69 (5), 689, 2007. 
